DOI: $10.14451 / 1.169 .76$

\title{
ЭКОНОМИЧЕСКОЕ ОБОСНОВАНИЕ РАЗВИТИЯ ЛОГИСТИЧЕСКИХ СЕРВИСОВ
}

\section{(C) 2018 Бедрин Денис Сергеевич}

Петербургский государственный университет путей сообщения Императора Александра I 190031, Санкт-Петербург, Московский проспект, 9

Целью данной статьи является представление результатов анализа моделирования 4PL логистики компании Samsung SDS. Моделирование основано на формализации современных мировых тенденций эволюции логистики от уровня 3PL до 4PL.При анализе различных видов логистики и их реинкарнации в логистические услуги более высокого уровня, в работе были использованы методы компиляции и интерпретации, метод адаптивных сравнений и реинжениринга бизнес процессов. Результатом данного исследования является: классификация и группировка методов перехода от 3-X к 4PL логистике. Объединены и формализованы основные решения и ценности, применяемые в современном управлении цепями поставок. Результаты проведенного исследования позволяют масштабировать предложенные решения на деятельность логистических компаний в РФ.

Ключевые слова: 3PL, 4PL логистика, открытая логистическая платформа, цепь поставок, глобальная логистическая сеть, контроль логистики.

\section{Введение:}

Современные тенденции развития мирового рынка таковы, что компании производители стараются фокусировать свои материальные и финансовые ресурсы на профильной деятельности, передавая выполнение второстепенных функций и сервисов дочерним компаниям или аутсорсерам. Аналогичная тенденция прослеживается и в логистике [1].

В полной мере данная тенденция наблюдается и в логистической сфере. Это позволяет компаниям производителям экономить на непрофильных издержках, относимых на стоимость основной продукции. В результате чего в мире значительно увеличилось количество логистических компаний - посредников, оказывающих услуги по комплексной логистике для своих клиентов [2].

Состояние современной логистики и уровень проникновения аутсорсинга 3PL и 4PL в цепи поставок это сложная проблема, находящаяся в постоянной дискуссии в научной и экспертной логистической среде [3]. Часть аналитиков полагает, что развитие 3PL операторов это не что иное, как превращение компании экспедитора в 4PL/LLP (lead logistics provider)- ведущего логистического оператора [4]. Есть мнение части экспертного сообщества, что 5PL логистика это теория. В действительности 5PL не что иное как модернизированная система 4PL [5]. В современном мире конкурентная борьба ведется как в сфере экономики, так и в политики. Политика чаще всего играет ведущую роль в информаци- онном пространстве. Поэтому страны Евросоюза, активно финансируют информационные технологии и планируют построить за ближайшие 10-20 лет единую логистическую информационную сеть, которая подтолкнет развитие 5PL логистики [6].

Резюмируя представленные выше рассуждения можно сделать вывод, что трансформация 3PL логистики в 4PL не простой эволюционный процесс. В настоящее время даже в промышленно-развитых странах пока еще нет предприятий, которые могут полностью отвечать теории конструкции 4PL логистики. После массового воодушевления конца 90-х начала 2000-х гг. концепция 4PL рассматривается некоторыми экспертами критически. И лишь меньшинство верит в будущее 4PL посредников [7].

Современной России характерно слабое развитие механизмов 4PL-сервисов, а так же отсутствие механизмов и регламентов предназначенных для работы виртуальных логистических посредников. При этом некоторые исследователи выявляют в России возможность прорывного перехода через эволюционный порядок развития логистического аутсорсинга и реализации на практике механизмов виртуального управления цепочками поставок 5PL [8].

\section{1. Эволюция логистики.}

Согласно мировой классификации логистического аутсорсинга выделяют 5 уровней логистического сервиса:

- 1PL - данный сервис характеризуется тем, что грузовладелец сам выполняет все логистиче- 
ские операции. Данная технология сформировалась еще в конце прошлого века.

- 2PL - частичный логистический аутсорсинга, при котором компания берет на себя часть логистических функций, например планирование, складирование, формирование логистической цепочки, но прибегает к привлечению сторонней транспортной компании, так как сама не обладает собственным транспортом.

- 3PL - комплексный аутсорсинг - это специализированная компания, которой поручается аутсорсинг всех или большей части логистических операций. Компании, относящиеся к данному типу, оказывают широкий спектр услуг, они не участвует в планировании всей логистической цепочки предприятия и не включены в хозяйственную деятельность производителя. Подрядчик оказывает комплекс услуг, в состав которых входят транспортировка товара, складирование, сквозное складирование, техническое управление складскими запасами, упаковка и экспедирование грузов.

- 4PL - интегрированный логистический аутсорсинг это сервис, при котором грузовладелец привлекает стороннюю логистическую компанию и дает ей право оказывать услуги не только по комплексной транспортной логистике, но и по планированию и проектированию цепочек поставок, передает ей задачи по управлению логистическими процессами. Сегодня большое количество крупных компаний пользуются услугами 4PL-провайдеров, например, GM, TOYOTA, HUINDAY и многие другие. Внедряя современные технологии логистики в свой бизнес, компании повышают свою конкурентоспособность и расширяют свое присутствие на мировом рынке [9].

- 5PL - «виртуальная» логистика, когда 4PL-провайдер начинает оказывать еще и услуги сетевого бизнеса, то он становится 5PL-оператором. Таким образом, это аутсорсер, который, используя глобальное информационно-технологическое пространство, способен оказывать весь спектр услуг. Яркими примерами 5PL-провайдеров можно назвать интернет-магазины, такие как eBay, Aliexpress, Amazon и др. [10]

В настоящее время ясно прослеживается мировая тенденция к переходу 3PL логистических операторов к 4PL или 5PL логистике.

Приведем наиболее вероятные способы достижения логистического провайдера четвертого уровня:
- логистический оператор 3-го уровня развивается до уровня 4PL;

- производитель продукта организует дочернее предприятие по образцу 4PL или переориентирует уже имеющееся дочернее предприятие на решение подобных задач;

- консалтинговое предприятие принимает роль 4PL;

- предприятие, предоставляющее услуги в области информационных технологий, становится 4PL;

- совместное предприятие из простого партнера по цепочке поставок становится 4PL.

По итогам 2017 года в рейтинге 50 транспортно-логистических компаний мира по полученной выручке - первое место досталось немецкой DHL logistics, второе и третье место Kuehne \& Nagel Швейцария и DB Schenker logistics германия, российских компаний в рейтинге не оказалось [11]. Необходимо отметить, что стратегия развития многих ведущих 3PL-операторов в 4PL базируется на развитии собственных технологических платформ. Например - XPO Logistics объявила о планах начала внедрения весной 2018 года мобильной платформы компании Drive XPO в Европе, после запуска в прошлом году в Северной Америке. В США JB Hunt Transport Services объявила о готовности вложить $\$ 500$ млн. в развитие своих информационных систем, облачной инфраструктуры, разработку и внедрение того, что компания объявляет «инновационными и революционными технологиями». Немецкая компания DHL, не первый год занимающая первое место в ТOП-50 крупнейших 3PL-операторов, недавно представила цифровую платформу CILLOX, которая связывает грузоотправителей и перевозчиков между собой ар всей Европе. DB Schenker в прошлом году приобрел за \$25 млн. долю в операторе платформы онлайн-бронирования грузоперевозок uShip [12].

2. Анализ моделирования 4PL логистики компании Samsung SDS и возможности его масштабирования.

Объектом анализа является предложение 4PL логистики от компании Самсунг. На сегодняшний день компания Samsung SDS предлагает ВРО (аутсорсинг бизнес процессов) охватывающий все стороны логистики, благодаря передовым информационным системам и глобальной логистической сети, включая консультации по внедрению инноваций в логистике, морские/ авиа/наземные авто и ж.д. перевозки, управ- 
ление складом и таможенное оформление. 4PL сервис, поддерживая логистику полного цикла, использует:

- опыт приобретенный в различных отраслях;

- глобальное управление процессами, инфраструктурой и сетью;

- единое решение охватывающее - закупки, логистические операции, документооборот, взаиморасчеты, анализ и оптимизацию.

Процесс объединяет: перемещение товара от производства до склада консолидации по средствам управления транспортом, таможенное оформление и доставку груза до порта отправки, далее экспедирование до порта назначения и интермодальные перевозки до регионального распределительного центра, дверную доставка до потребителя, логистику возвратов к поставщикам, управление договорами с перевозчиками и управление рисками, которое замыкается на производстве. Ценность данного предложения для компании производителя можно разделить на три группы:

1. Преимущества эффективной закупки:

- находясь в топ 10 по грузообороту компания может предложить качественные услуги по разумной цене;

- сокращение логистических затрат за счет контроля состояния и оптимизации маршрутов, сетевое планирование.

2. Повышение операционной эффективности:

- настраиваемые под клиента процессы в рамках операционной сети;

- платформа знаний по логистике для расширения возможностей клиентов;

- глобальная логистическая сеть и накопленный исключительный практический опыт, высокое качество услуг.

3. Улучшение контроля:

- глобальный центр управления, поддержка операции по всему миру в режиме онлайн;

- удобный доступ к информации в любое время в любом месте с любого устройства;

- информация об отклонениях в режиме реального времени.

В итоге предлагается три решения: Cello ВРО - полный комплекс логистических услуг,

Cello SQUARE - открытая логистическая платформа, Cello PLUS - комплексное решение для цепи поставок. Все они объединяют задачи логистики в бизнесе, технологиях и индустрии
[13].

Cello SQUARE - можно назвать новой экосистемой глобальной логистики. Ее основные функции делятся на две группы: управление рисками при доставке грузов и платформа электронной коммерции Cello EXPRESS. Управление рисками позволяет получать информацию о свободном транспорте, наличии места на борту самолета, свободном пространстве на судне, график движения транспорта и расписание рейсов, обзор маршрутов и мониторинг движения грузов для предотвращения потенциальных рисков.

Cello EXPRESS имеет следующий функционал:

- блок закупок, позволяющий произвести эффективные закупки услуг логистики на весь объем грузов;

- единый координационный центр позволяет отслеживать грузы на любом этапе доставки;

- гарантированная гибкость - дает возможность эффективно работать с огромным пулом перевозчиков по всему миру.

Трансграничная экспресс платформа дает возможность корпоративным заказчикам и поставщикам экспресс услуг получать лучшие тарифы благодаря большому объему заказов и получать услугу в режиме одного окна: тарификация, выставление счета, отслеживание. Передовые информационные технологии позволяют системе вести трекинг в режиме реального времени с перевозчиками в 80 странах. Сбор и анализ больших данных (Big data) для оценки рисков и выработки планов противодействия угрозам, включает сбор метеоданных о стихийных бедствиях, авариях, воздействия социальных и политических факторов более чем в 20000 источниках.

Cello PLUS в единой платформе объединяет девять модулей обеспечивающих поддержку всех звеньев цепочек поставок:

1. Планирование - предсказывает спрос на продукцию на рынке и на этой основе формирует стратегию управления цепочками поставок и оптимальное распределение ресурсов.

2. Закупки - обеспечивает выбор лучшего поставщика: авиалинии, морские линии, ж.д., авто, транспортные компании.

3. Транспортный модуль - выбирает оптимальные режимы и маршруты доставки.

4. Глобальная торговля - обеспечивает эффективную логистику в глобальном масштабе, 
предоставляя платформу для совместной работы в любой точке мира.

5. Складское хранение - обеспечивает эффективное управление складом, используя лучшие практики и четко отработанные стандарты.

6. Прогнозирование - в нем система искусственного интеллекта проводит анализ огромных массивов данных, которые дают основу для прогнозирования оперативной работы.

7. Управление рабочим процессом - обеспечивает следование стандартам, управления знаниями и помогает контролировать риски.

8. Аналитический - собирает данные о выполнении логистических процессов и предоставляет различные типы аналитической информации.

9. Общий модуль - обеспечивает глобальное управление функционалом и процессами в Cello, включая: заказы, договорную работу, финансы.

Cello PLUS в глобальной и децентрализованной бизнес-среде наделяет своих пользователей мощным инструментом управления цепочками поставок с учетом их непрерывности, гибкости, передовых технологий и совершенных процессов. Это есть:

- передовые технологии - базирующиеся на “интернете вещей” системы отслеживания грузов и оценки рисков, анализ больших данных для точного прогнозирования, функции с алгоритмами оптимизации: склад и сетевое моделирование;

- предложения по запросу - варианты решения и услуги адаптированные под нужды клиента, консалтинг и аутсорсинг логистики;

- лучшие практики - предложение проверенных и усовершенствованных процессов наряду с инновациями, глобальное логистическое планирование, оптимизация запасов, оптимизация прибыли.

B итоге Cello предлагает логистические услуги, удовлетворяющие особым требованиям различных отраслей, например: электроники и высоких технологий, энергетике, автомобильной промышленности, проектированию и строительству, розничной торговле. Так же предоставляет услуги для бизнеса: управление закупками, международная доставка, управление складом, доставка “до двери”, логистика возвратов, внутрипроизводственная логистика, авто и ж.д. доставка, управление дистрибуцией и распределительным центром, экспресс достав- ка и логистика сервис центров. Стоит отметить и специализированные решения приносящие пользу клиентам: контроль и видимость всей цепочки поставки, система умный склад, сетевое планирование, система анализа и оценки эффективности цепочки поставки.

Детально осветив предложение 4PL логистики от компании Самсунг необходимо подчеркнуть, что по итогам 2017 года компания заняла 23-место по выручке в рейтинге 50 транспортно-логистических компаний мира и ее место постоянно растет.

\section{Результат и практическая значимость:}

4PL-подход призван оптимизировать цепь поставок для компании производителя в целом за счет влияния на следующие составляющие: рост спроса на логистический сервис, сокращение затрат на перевозки, увеличение времени оборота капитала, снижения сроков доставки грузов, улучшения контроля за перевозками в режиме реального времени [14]. Для получения более высоких операционных показателей перечень услуг 4PL-посредника должен включать: создание контроль и оптимизацию перевозок, разработку и управление логистикой, отслеживание исполнения заказов, планирование оптимальных маршрутов, контроль материальных потоков, интегрированное управление запасами и добавленной стоимостью, менеджментом качества и лизингом транспортных возможностей, ведение единого документооборота [15].

Снижение операционных затрат производителей достигается за счет синхронизации деятельности, информационных потоков и технологий между участниками цепи (производителя и 4PL оператора), что приводит к сокращению операционных затрат, снижению цены на товар благодаря интеграции процессов, улучшению планирования и выполнения логистических задач [16]. Сокращение рабочего капитала компании производителя произойдет в результате эффективного управления запасами и их снижению. Технологии управления заказами и отслеживания грузов приведут к минимизации необходимых запасов производителя.

Снижение уровня основного капитала будет следствием передачи управления компании 4PL, а также более эффективным использованием средств. Передача физических активов 4PL-компаниям позволит освободить ресурсы производителя для инвестиций в объекты профильной деятельности компании. Кроме описанных 
выше плюсов следует перечислить риски при переходе к 4PL логистике:

- уменьшение степени влияния на процессы логистики и их контроля;

- утрата специфического подхода к работе;

- потеря клиента или поставщика из-за отсутствия доверия к подрядчику;

- снижение качества выполнения операций;

- поручения подрядчику не правильных функций, ведущих к будущим потерям.

Очевидно, что на практике сохранение функций логистики внутри компании экономически невыгодно, так как затраты на содержание собственного подвижного состава (судов, вагонов, самолетов, автопарка) постоянны, а объём грузопотока постоянно меняется. Поэтому подвижной состав, работающий под нужды одного клиента в большинстве случаев является нерентабельным, так как не способен максимально эффективно использовать постоянство загрузки и отсутствие порожних пробегов.

\section{Заключение:}

Мировая глобализация, интеграция, кооперация, а также все более возрастающие запросы потребителей на качество логистического обслуживания побуждают компании, которые хотят быть конкурентоспособными на рынке, использовать логистический аутсорсинг - 4PL. Поэтому процесс перехода 3PL операторов в интеграторы логистических процессов более высокого уровня 4 и 5PL - неотвратим. Предложенная модель, путем нового подхода к экосистеме глобальной логистики, дает возможность комплексно подойти к решению задач 3PL оператора при его переходе на 4PL. Системность, модульность и дифференцированный подход к разным отраслям промышленности позволяет принять на вооружение предложенную технологию перехода и масштабировать ее на предприятия логистического сектора РФ.

\section{Библиографический список}

1. Аутсорсинг и лизинг персонала [Электронный ресурс] // Аутсорсинг в логистике. 2014. URL: http://www. autsorsing.net/autsorsing-v-logistike-das/

2. 8 reasons to outsource logistics services: https://www.flatworldsolutions.com/logistics/articles/outsourcelogistics-services-8-reasons.php

3. Аникин Б.А., Родкина Т.А. Логистика и управление цепями поставок. Теория и практика. Москва. 2018, C.78-91.

4. 2016 Third-Party Logistics Study: The State of logistics outsourcing. Results and findings of the 20th annual studyhttps://www.kornferry.com/media/sidebar_downloads/2016_3PL_Study.pdf

5. 5PL - «Нет ничего сильнее идеи, время которой пришло» [Электронный ресурс]. Режим доступа: http:// transport-journal.com/news/autotransport-i-dorogi/5pl-net-nycheho-sylnee-ydey-vremya-kotoroj-pryshlo/

6. Ежова В.О. Логистический аутсорсинг в России: проблемы и пути решения / В.О.Ежова, А.Г. Афанасьева // Актуальные вопросы экономики и управления: материалы III междунар. науч. конф. Москва. 2015.

7. Зубаков Г. Виртуальные логистические операторы / Г. Зубаков, И. Проценко // КТР: Маркетинг \& Логистика. 2010. № 2. C. 36-41.

8. Курамшин Н.Д. $5 \mathrm{pl}$ - новый уровень логистического аутсорсинга: // Успехи современной науки и образования статья. https://elibrary.ru/item.asp?id=26539962

9. Свой бизнес: логистический провайдер [Электронный ресурс]. Режим доступа http://www.openbusiness.ru/ biz/business/svoy-biznes-logisticheskiy-provayder/

10. ТОП-50 3PL-операторов 2017 года: https://ogist.today/2018/04/18/top-50-3pl-operatorov-2017-godavyruchka-kompanij-vyrosla-na-10-3/

11. Zinn H. Fourth Party Logistics: Mehr alsnur ein Modebegriff? // Logistik heute. 2002. № 9. P. 36.

12. 5 уровней логистического сервиса: www.logist.ru

13. Cello BPO, Cello SQUARE, Cello PLUS: www.samsungsds.com

14. Patrick Burnson- April 1, 2013: Global Logistics: Demystifying the 4PLhttps://www.logisticsmgmt.com/article/ global_logistics_demystifying_the_4pl

15. Shell: first-in-industry 4PL logistics solution. https://www.accenture.com/t20150818T105035Z_w_/usen/_ acnmedia/Accenture/Conversion-Assets/DotCom/Documents/Global/PDF/Dualpub_10/Accenture-ShellAchieving-Step-Change-Logistics-Prformance.pdfla=en

16. 8 Reasons to Outsource Logistics Serviceshttps://www.flatworldsolutions.com/logistics/articles/outsourcelogistics-services-8-reasons.php 